DOI 10.37882/2223-2982.2020.09.05

\title{
СОВРЕМЕННЫЕ ТЕХНОЛОГИИ СОВЕРШЕНСТВОВАНИЯ НАВЫКОВ ПРАВИЛЬНОГО ФОНАЦИОННОГО ДЫХАНИЯ У ИНОСТРАННЫХ СТУДЕНТОВ-МЕДИКОВ (В КОНТЕКСТЕ ОБУЧЕНИЯ КУЛЬТУРЕ НАУЧНОЙ РЕЧИ И ПРОФЕССИОНАЛЬНО-ДЕЛОВОМУ ОБЩЕНИЮ)
}

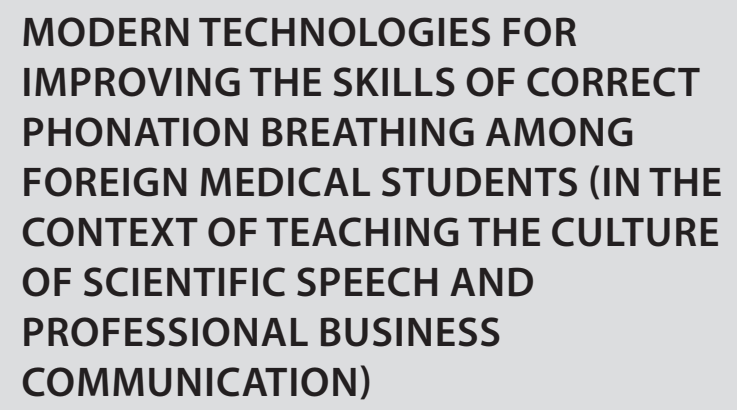

MODERN TECHNOLOGIES FOR IMPROVING THE SKILLS OF CORRECT PHONATION BREATHING AMONG FOREIGN MEDICAL STUDENTS (IN THE CONTEXT OF TEACHING THE CULTURE OF SCIENTIFIC SPEECH AND PROFESSIONAL BUSINESS COMMUNICATION)

\section{R. Arzumanova}

Yu. Gosteva

Summary: The analysis of modern technologies for the formation of correct phonation breathing skills in foreign medical students gives grounds to assert that the formation of phonation breathing skills allows teaching the culture of scientific Dialogic and monological oral speech, professional and business communication. The project presents and systematizes modern technologies for the formation of proper phonation breathing skills. Exercises on formation of skills of correct phonation breathing are described. Methodological recommendations for teachers on the use of modern technologies for the formation of phonation breathing skills of foreign medical students are presented.

Keywords: modern technologies, formation of skills of correct phonetic and phonation breathing, speech development, foreign medical students.

\section{Введение}

Выявление и анализ эффективных технологий современных технологий совершенствования навыков правильного фонационного дыхания у иностранных студентов-медиков обусловил этапы работы над проектом:

1. уточнение понятийного аппарата;

2. уточнение основных критериев правильного фонационного дыхания;

3. систематизация фонационных навыков студентов-медиков;

4. характеристика контекстной обусловленности формирования фонационных навыков как мотивирующего фактора;

5. операционализированное описание современ-
Арзуманова Раиса Аркадьевна

К.п.н., дочент, Российский университет дружбы народов arzumanowa@mail.ru

Гостева Юлия Николаевна К.п.н., дочент, Российский университет дружбы народов ulianik@mail.ru

Аннотация: Анализ современных технологий формирования навыков правильного фонационного дыхания у иностранных студентов-медиков даёт основание утверждать, что сформированность навыков фонационного дыхания позволяет обучить культуре научной диалогической и монологической устной речи, профессионально-деловому общению. В проекте представлены и систематизированы современные технологии формирования навыков правильного фонационного дыхания. Описаны упражнения по формированию навыков правильного фонационного дыхания. Представлены методические рекомендации для преподавателей по использованию современных технологий формирования навыков фонационного дыхания иностранных студентов-медиков.

Ключевые слова: современные технологии, формирование навыков правильного фонетического и фонационного дыхания, развитие речи, иностранные студенты-медики.

\begin{abstract}
ных технологий формирования навыков правильного фонационного дыхания у иностранных студентов-медиков в контексте обучения культуре научной речи и профессионально-деловому общению.
\end{abstract}

Фонационная компетенция представляет собой характеристику степени усвоения совместной осознанной работы артикуляционных органов и органов дыхания во время произнесения речевых и вокальных звуков. Фонационное или речевое дыхание играет большую роль при создании звуков речи. При фонационном дыхании производство звуков происходит произвольно, вдох становится короче, выдох, в свою очередь, является замедленным, прерывистым, подчиненным произ- 
несению текста, очередной вдох происходит без паузы.

При произнесении звуков речи выгоняемая воздухом струя встречается с сомкнутыми и напряженными голосовыми связками. При колебании голосовых связок в голосовой щели образуется разряженные потоки выдыхаемого воздуха в струе. Такие воздушные колебания образуют звуки речи. Выдох речи обычно происходит через ротовую полость. Лишь небольшие порции выдыхаемого воздуха проходят через нос, образуя произношение отдельных звуков. Фонация звуков сопровождается реберно-диафрагмальным типом дыхания, осуществление которого происходит в результате сокращения диафрагмы и межреберных мышц. Для того чтобы исполнить песню или произнести речь человеку необходимо изменение естественного газообменного реберно-диафрагмального типа дыхания для создания благоприятных условий с целью осуществления деятельности речевого аппарата.

\section{Изложение основного материала исследования}

Основными критериями создания правильного фонационного дыхания являются следующие характеристики: при правильном фонационном дыхании

- не осуществляется перегрузка воздуха легкими;

- работа голосовых связок не ориентируется на давление воздуха;

- максимально смягчается подвязочное давление;

- происходит минимальное дыхательное движение грудной клетки;

- осуществляются минимальные затраты воздуха в связи с голосовыми изменениями по высоте и силе затрат;

- голосовые связки сохраняют свои функции в процессе речи;

- при производстве речи участвуют все дыхательные мышцы;

- органы грудной клетки и верхней части речевого аппарата освобождены от напряжения;

- при необходимости ротовая полость может достичь максимального расширения.

Опираясь на исследования внешней структуры речевой деятельности, мы определяем фонационные навыки как способность иностранного студента-медика осуществлять самостоятельное речевое воздействие на операциональном уровне, благодаря которому при осуществлении всех требований повышается сложность произнесения запланированных речей.

Можно систематизировать фонационные навыки иностранных студентов-медиков. К первой группе относятся технологические навыки,

представляющие собой особенности правильного произношения звуков при произнесении запланированных речей и исполнении вокальных номеров, с четкой артикуляцией, хорошей дикцией, с выполнением фразового и словесного ударения. При этом может произойти изменение динамического диапазона с целью достижения выразительности речи. Необходимо соблюдать рациональное использование дыхательной системы для достижения беглого говорения при нормальном восприятии речи (до 5 слогов в секунду).

Ко второй группе относятся художественно-эмоциональные фонационные навыки, при которых соблюдается мелодический рисунок; сохраняется интонационное оформление, как при осуществлении устного высказывания, применяется тембровая окраска, соответствующая ситуации и задачам высказывания; во фразе логически выделяется лексема или словосочетание.

Третью группу представляют рефлексивно-оценочные фонационные навыки, благодаря которым проявляются способности внесения элементов новизны в осуществление речеголосовой деятельности. Кроме этого, выявляются способности к демонстрации творческих способностей и проявлению качеств импровизации [Аристова, 2005, 16].

Речевая деятельность как реализация активного целенаправленного процесса восприятия или порождения речи имеет непосредственный предмет, продукт, результат, а также средства и уникальные способы реализации формы общения. Поэтому необходимо формировать гибкость и автоматизированность навыка речевой деятельности с помощью осуществления контекстной обусловленности. Предметное содержание занятий по обучению культуре научной речи и профессионально-деловому общению позволяет обеспечить образовательную среду для успешного совершенствования навыков фонационного дыхания иностранных студентов-медиков, что способствует, в свою очередь, развитию диалогической и монологической устной речи.

По мнению И.А. Зимней, любой речевой навык завершает свое формирование лишь при достижении оптимального уровня совершенства действия речи, т.е. операционального аспекта деятельности [Зимняя, 1974, 64]. Следует отметить, что отсутствие контроля со стороны сознательной деятельности направлено на достижение последовательности и правильности исполнения действий речевого навыка.

Проведённый анализ современных технологий совершенствования фонационных навыков позволил выявить наиболее эффективные, среди которых - интерактивные диалоговые (в том числе цифровые) технологии; проектная технология как современный способ 
развития в ходе исследовательской деятельности осознанного отношения иностранных студентов-медиков к речевой среде и собственной речи. Интерактивные диалоговые (в том числе цифровые) технологии позволяют в контексте профессиональных интересов и профессионально значимых навыков иностранных студентов-медиков обеспечить совершенствование фонационных навыков всех трёх групп (см. выше).

Использование интерактивных диалоговых технологий (дебатов, дискуссий) позволяет формировать и совершенствовать коммуникативные навыки грамотного ведения полемики, отстаивания своей точки зрения на основании полученных знаний и логических суждений, сопоставления, сравнения и самостоятельного поиска и анализа информации, полученной из разных источников.

Кроме того, эти технологии развивают у иностранных студентов-медиков навык правильного произношения звуков речи при демонстрации речевого или вокального режима работы голоса; навык четкой артикуляции; особенности владения фразовым и словесным ударением. Кроме этого, студенты-медики получат возможность управлять силой своего голоса для достижения выразительности речи; научиться рационально использовать дыхание; совершенствовать беглое говорение в формате нормального восприятия (до 5 слогов в секунду), а также интонационное оформление речи, соответствующее содержанию устного высказывания; тембровую окраску голоса в соответствии с ситуацией и задачей высказывания, умение вносить элементы новизны в речевую деятельность, импровизировать.

Проведению дебатов должна предшествовать большая подготовительная работа, и важный этап подготовки - это формулировка темы. Тема должна затрагивать значимые проблемы, быть актуальной, представлять интерес для сторон, быть пригодной для спора. Для того чтобы помочь иностранным студентам-медикам в подборе аргументов, им предлагаются материалы упражнений, публикации периодических изданий, материалы Интернета. Для подготовки к дебатам можно использовать приём «параллельные тексты»: организация работы с текстами, имеющими аргументы в поддержку различных точек зрения. Приём может быть реализован при работе, как минимум, с двумя текстами, в которых выражены различные мнения по одному и тому же вопросу. Первый, как правило, отражает наиболее распространённое мнение, второй текст нужно подобрать так, чтобы он это распространённое мнение оспаривал.

Постоянное и динамичное развитие цифровых технологий открывает новые возможности использования теоретических и практико-ориентированных электронных курсов, предоставляющих широкие возможности индивидуализации учебного процесса с учетом способностей каждого обучающегося. Основными направления использования цифровых технологий в образовательном процессе можно считать следующие: 1) использование специально разработанных для иностранных студентов-медиков цифровых образовательных ресурсов; 2) использование ресурсов сети Интернет, созданных для всеобщего использования, но обладающие потенциалом для решения образовательных задач, в том числе задач формирования навыков фонационного дыхания.

Преимуществом проектов в практике формирования фонационных навыков становится возможность преподавателя спроектировать работу с образцовой видеолекциями; организовать работу по самостоятельному изучению материалов, размещённых на различных образовательных платформах.

Использование ресурсов сети Интернет, созданных для всеобщего использования, но обладающих потенциалом для решения образовательных задач может стать одним из мотивирующих факторов совершенствования фонационных навыков иностранных студентов-медиков при обучении русскому языку. Данные ресурсы можно классифицировать следующим образом:

1. Ресурсы сети Интернет с контентом, направленным на развитие и поддержку русского языка (сайты «Грамота.ру» (http://gramota.ru/), «Грамма. py» (http://gramma.ru/), «Текстология» (http://www. textologia.ru/), «Национальный корпус русского языка» (http://www.ruscorpora.ru/). портал «Сoвременный русский» (http://www.oshibok-net.ru/ for-all/).

2. Ресурсы сети Интернет с контентом, необходимым для решения задач по совершенствования фонационных навыков иностранных студентов-медиков при обучении русскому языку, но не являющиеся специально для этого созданными (поисковые системы, сайты музеев, театров, выставок и пр.).

3. Электронные библиотеки со справочниками, энциклопедиями, словарями, учебной и классической художественной литературой (например, Академик (https://dic.academic.ru/), сайт «По́лка» (https://polka.academy/))

4. Художественные и документальные фильмы, мультфильмы, архивные видеозаписи, видеозаписи театрализованных постановок и пр.

С целью совершенствования фонационных навыков иностранных студентов-медиков при обучении русскому языку могут использоваться современные мессенджеры (например, Viber, WhatsApp), а также средства текстовой и аудиовизуальной связи (например, электронная почта и Skype).

Рассмотрим для примера некоторые возможности 
использования справочно-информационного портала «Грамота.ру».

Несомненно, в процессе совершенствования фонационных навыков иностранных студентов-медиков при обучении русскому языку особое место уделяется прослушиванию озвученных текстов. Для этого необходимо обратить пристальное внимание на орфоэпические особенности произнесенного диктором текста, а также тему, раскрывающую его лексические особенности. На портале «Грамота.ру» размещен аудиословарь «Русский устный», с помощью которого обучающиеся смогут в интересной форме познакомиться с русской фразеологией, незнакомыми фразеологическими сочетаниями и сращениями, пословицами и поговорками. Кроме этого, в увлекательной форме студенты имеют возможность получить новые сведения о русской культуре, об особенностях классической и современной литературы, этимологического происхождения незнакомых лексем.

Необходимо отметить словарь «Говорите правильно», действующий на портале «Грамота.ру». Здесь ведущие ведут непринужденную беседу о трудностях русской орфоэпии, произношения слов, а также о лексических и грамматических особенностях русского языка. Тематика выпусков «Словаря ударений» определяется формулировкой наиболее частых вопросов, размещенных в разделе «Справочное бюро» портала.

\section{Зак^ючение}

Мы отметили, что аудирование способствует развитию и совершенствованию навыка правильного произношения слов и умению уместного употребления лексем с учетом их лексического значения.

Однако использование цифровых ресурсов имеет некоторые ограничения для обучающихся. В качестве примера можно привести особенности обучающих программ и электронных учебных пособий, которые являются программами закрытого типа и контролируются компьютерной системой. Поэтому в целях обеспечения живого общения при использовании цифровых ресурсов целесообразно предлагать иностранным студентаммедикам учебное сотрудничество, организуя работу в парах и в малых группах.

\section{ЛИТЕРАТУРА}

1. Аристова Е.А. Развитие у студентов вуза фонетических и фонационных навыков иноязычной устной речевой деятельности // Вестник ПниПу. Проблемы языкознания и педагогики. 2014. №9. URL: https://cyberleninka.ru/article/n/razvitie-u-studentov-vuza-foneticheskih-i-fonatsionnyh-navykov-inoyazychnoyustnoy-rechevoy-deyatelnosti (дата обращения: 11.02.2020).

2. Соколов А.Н. Автореферат диссертационного исследования. Внутренняя речь и мышление 1968, c.56-57 URL: http://irbis.gnpbu.ru/Aref_1967/ Sokolov_A_N_1967.pdf

3. Алексеева Ирина Николаевна восстановление фонационного (речевого) дыхания у больных с дизартрией в раннем восстановительном периоде инсульта (из опыта работы логопеда) // Евразийский Союз Ученых. 2015. №4-5 (13). URL: https://cyberleninka.ru/article/n/vosstanovlenie-fonatsionnogorechevogo-dyhaniya-u-bolnyh-s-dizartriey-v-rannem-vosstanovitelnom-periode-insulta-iz-opyta-raboty-logopeda (дата обращения: 11.02.2020).

4. Белякова Л.И., Дьякова Е.А. Заикание. Учебное пособие для студентов педагогических институтов по специальности “Логопедия" - М.: В. Секачев, 1998 URL: http://pedlib.ru/Books/2/0015/2-0015-39.shtml

5. Бурачевская 0.В., Бурачевская Т.В., Бурачевская Н.И. Возможности использования компьютерных технологий в работе с людьми с нарушениями речи // Вопросы педагогики. — 2017. — №3. - C. 21-26. — URL https://moluch.ru/th/1/archive/63/2608/ (дата обращения: 11.02.2020).

6. Арзуманова Р.А., Гостева Ю.Н., Зеленова 0.В. Современные технологии развития речи в формировании правильного фонационного дыхания у иностранных студентов // Современная наука: актуальные проблемы теории и практики. Серия «Гуманитарные науки», —2020. - № 3. - C. $39-42$

7. Зимняя И.А. Речевая деятельность и психология речи // Основы теории речевой деятельности / Под ред. А.А. Леонтьев. - М.: Наука, 1974. - С. 64-72. 